\title{
A comparison of three different corneal marking methods used to determine cyclotorsion in the horizontal meridian
}

This article was published in the following Dove Press journal:

Clinical Ophthalmology

8 February 2017

Number of times this article has been viewed

\author{
Hung-Yuan Lin ${ }^{1-3}$ \\ Yi-Ting Fang ${ }^{4}$ \\ Ya-Jung Chuang ${ }^{5}$ \\ Justin N Karlin 6 \\ Hsin-Yang Chen ${ }^{7}$ \\ Szu-Yuan Lin ${ }^{8}$ \\ Pi-Jung Lin ${ }^{9}$ \\ Ming Chen ${ }^{10}$
}

'Universal Eye Center, Zhong-Li,

Taiwan, Republic of China;

${ }^{2}$ Department of Optometry, Central

Taiwan University of Science and

Technology, Taichung, Taiwan,

Republic of China; ${ }^{3}$ Department

of Ophthalmology, Fu-jian Medical

University, People's Republic of

China; ${ }^{4}$ Universal Eye Center, Taoyuan,

Taiwan, Republic of China; ${ }^{5}$ Universal

Eye Center, Long-Tan, Taiwan,

Republic of China; ${ }^{6}$ Department of

Ophthalmology, University of Virginia,

Charlottesville,VA, USA; ' Department of Ophthalmology, Ningbo First

Hospital, People's Republic of China;

${ }^{8}$ Department of Ophthalmology,

Cathay General Hospital, 'Universal

Eye Center, Taipei, Taiwan, Republic

of China; ${ }^{10}$ Department of Surgery,

Division of Ophthalmology, John A

Burns School of Medicine, University

of Hawaii, Honolulu, HI, USA

Correspondence: Ming Chen Department of Surgery, Division of Ophthalmology, John A Burns School of Medicine, University of Hawaii, I 356 Lusitana Street, Honolulu, HI 968I3, USA

Tel +l 80853 I 8874

Email mingchen@hawaii.rr.com
Abstract: During toric intraocular lens (IOL) implantation, surgeons must take particular care to ensure that inaccurate preoperative measurement and intraoperative misalignment do not cause unexpected postoperative residual astigmatism. This retrospective, comparative case series study aimed to analyze the rotational deviation, or cyclotorsion, of three corneal marking methods: VERION digital marker (VDM; reference), horizontal slit beam marking (HSBM), and subjective direct visual marking (SDVM) on the table (using a bevel knife tip). Subjects included 81 eyes of 61 patients (mean age: $65.70 \pm 13.14$ years; range: $32-91$ years) undergoing scheduled cataract surgery. A preoperative reference image was taken of each eye. Subsequently, a slit lamp with the light beam turned to the horizontal meridian was used to align the seated patient's head, and two reference marks were placed at the 3- and 9-o'clock positions of the corneal limbus using a 27-gauge needle and marking pen (HSBM). Upon transfer to the surgical table, the VDM was used to display a real-time dial scale on the patient's eye, with the entrance of the temporal clear corneal incision (CCI) at $0^{\circ}$ (horizontal meridian). Simultaneously, a bevel knife tip was used to create a marker based on the surgeon's visual determination of the temporal $0^{\circ}$ point (SDVM). We used the VDM to quantitatively evaluate the accuracy of axis alignment via deviation from the horizontal reference meridian. Compared with the reference meridian, the SDVM $\left(-3.46^{\circ} \pm 7.32^{\circ}\right.$, range: $-18^{\circ}$ to $\left.13^{\circ}\right)$ exhibited greater average relative cyclotorsion versus the $\operatorname{HSBM}\left(0.41^{\circ} \pm 4.92^{\circ}\right.$, range: $-10^{\circ}$ to $\left.10^{\circ}\right)$. Furthermore, the mean average misalignment was significantly less in the HSBM group versus the SDVM group ( $t=4.179, P<0.001)$. The VDM is likely a reliable marking method, similar to the HSBM. In contrast, the SDVM is not entirely reliable. The VDM usage may prevent inaccurate preoperative manual marking during toric IOL implantation.

Keywords: VERION digital marker, horizontal slit beam marking, subjective direct visual marking

\section{Introduction}

Astigmatism correction has become an increasingly important component of cataract surgery as surgeons aim to meet the high refractive expectations of patients, especially with respect to "spectacle independence". Of late, toric intraocular lens (IOL) implantation provides a reliable and effective method for meeting these expectations; however, surgeons must take particular care to ensure that inaccurate preoperative measurements and intraoperative misalignments (eg, head tilt and cyclotorsion caused by positional changes) do not result in unexpected postoperative residual astigmatism.

Accurate corneal marking is a critical step when orienting the axis of a toric IOL within the capsular bag. Currently, various marking techniques and modalities are used 
to identify the horizontal $\left(0^{\circ}\right.$ to $\left.180^{\circ}\right)$ meridian, with which the marks present on the IOL should be aligned. ${ }^{1-4}$ Notably, errors in alignment may induce deviation from the correct meridian. According to Hill and Potvin, ${ }^{5}$ every $1^{\circ}$ where the toric IOL is "off axis" will yield a $3.3 \%$ reduction in cylinder correction. Deviation from the median can be attributed to several mistakes, including inaccurate preoperative prediction of the correct axis for IOL alignment, inaccurate preoperative marking of the horizontal meridian, and inaccurate surgical implantation. In our experience, preoperative corneal marking is generally the most crucial step in preventing IOL misalignment. Therefore, we aimed to determine the degree to which several corneal marking methods would impact IOL misalignment.

The VERION Image Guided System (Alcon Laboratories, Ft. Worth, TX, USA), which includes the VERION reference unit and VERION digital marker (VDM), was first evaluated by clinical trials in 2013. The reference unit is used preoperatively to perform diagnostic measurements. These include documentation of scleral vessels and iris structures, corneal radii, pupillometry, and the white-to-white (WTW) distance. The digital marker is located in the operating room, where the information is acquired and calculated by the reference unit and can be displayed in the surgeon's microscope. Using an eye-tracking function, it can display the axis of main wound incision (eg, the horizontal meridian $0^{\circ}$ or $180^{\circ}$ ) and the axis for implantation of a toric IOL to eliminate the need for manual preoperative corneal marking. ${ }^{6}$ The VERION reference unit captures a digital registration of the eye that can be used to map the center of the undilated pupil, scleral vessels, limbus, and landmarks of the iris while measuring keratometry, pupil diameter, and the magnitude of astigmatism; however, the use of this device raises questions regarding the degree to which the astigmatism axis identified by this system compares with that of traditional marking techniques. Therefore, our study aimed to record and analyze the rotational deviation associated with the three corneal marking methods: VDM, subjective direct visual marking (SDVM) on the table (using a bevel knife tip), and horizontal slit beam marking (HSBM).

\section{Methods}

This comparative, retrospective case series included 81 consecutive eyes of 61 patients. All patients underwent cataract surgery at the Universal Eye Center, Zhong-Li, Taiwan, between December 2014 and April 2015. All patients were informed about the risks and benefits prior to cataract surgery and provided written informed consent in accordance with the institutional guidelines and the Declaration of Helsinki regarding human research. The present study was approved by the Institutional Review Board of Antai Tian-Sheng Memorial Hospital (17-004-B1). Patients included in the study had an unremarkable ocular history except for cataracts. The exclusion criteria included sensory nystagmus, previous ocular or intraocular surgery, acute or chronic corneal infection, and inflammatory conditions of the cornea detected via slit lamp examination.

All patients underwent standard preoperative examinations to confirm the axis and power of astigmatism, including automated keratometry, KR-8800 (Topcon Corp., Tokyo, Japan), optical biometry (AL-Scan; NIDEK Co., Ltd., Gamagori, Japan or LENSTAR LS-900; HAAG-STREIT Diagnostics, Köniz, Switzerland), and VERION digital marking. Each cataract surgery was performed using a CENTURION system (Alcon), VERION image guidance system, and Luxor microscope (Alcon). Surgical procedures were videotaped, and VERION images were captured during temporal clear corneal main wound creation and used for subsequent analysis. All procedures were performed by one surgeon (HY Lin), and the patients were administered topical anesthesia. In all cases, a $2.4 \mathrm{~mm}$ temporal CCI was made (in both eyes), and a $6.0 \mathrm{~mm}$ foldable IOL was implanted in the capsular bag. Postoperatively, all patients received similar combination treatment regimen, which comprised an antibiotic and a steroid.

\section{Preoperative corneal marking techniques VDM}

The VERION reference unit captures a preoperative reference image, and the VDM displays a dial scale on the patient's eye in real time to indicate the entrance of the temporal CCI at $0^{\circ}$ (ie, the horizontal meridian; Figure 1).

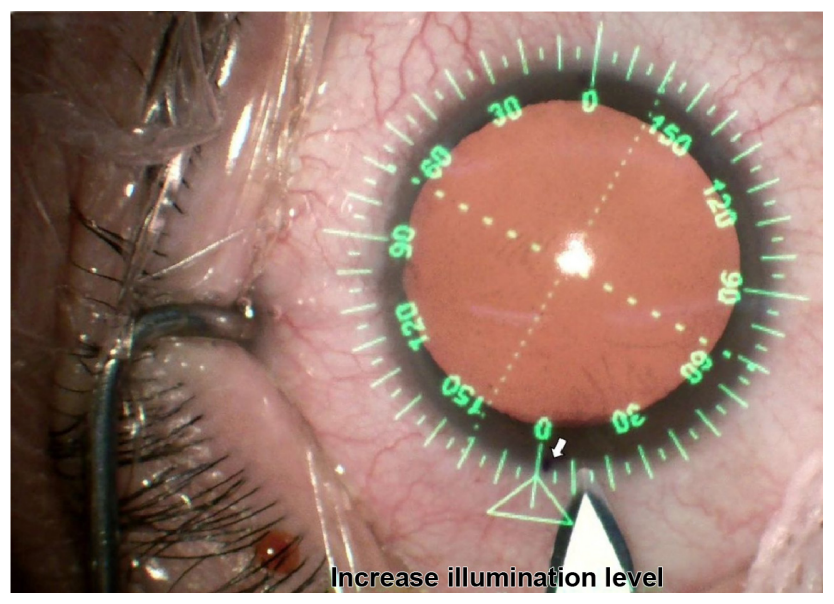

Figure I Demonstration of three methods of corneal-limbus position marking: VERION digital marker (green), subjective direct visual marking on the table (bevel knife tip), and horizontal slit beam marking (white arrow, thin blue dot). 


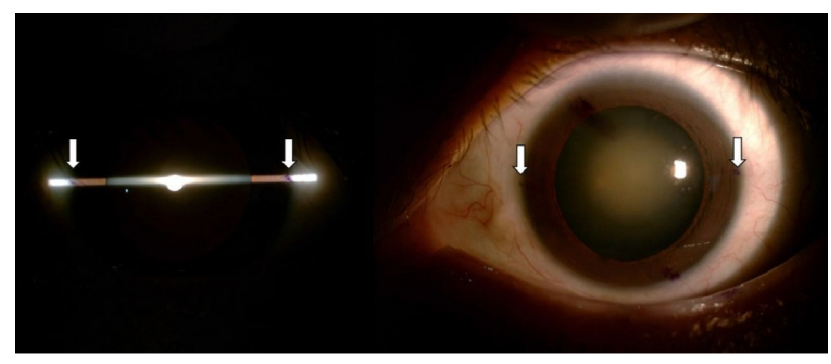

Figure 2 Perfect alignment of the horizontal slit beam marker (white arrow, thin blue dot).

Note: We avoided using the relatively thicker pen tip marker, which would produce ink marks with a width of at least $2^{\circ}$.

\section{SDVM}

While the patient was on the surgical table, a bevel knife tip was used to make a mark at the temporal $0^{\circ}$ point under unassisted vision (ie, naked eye; Figure 1).

\section{HSBM}

The slit beam was turned to the horizontal position and centered on the corneal apex of the patient after ensuring a lack of head tilt. The horizontal axis $\left(0^{\circ}\right.$ and $180^{\circ}, 3$ and 9 o'clock) was marked on the corneal limbus using a 27 -gauge needle and marking pen (Accu-line Products, Inc., Hyannis, MA, USA) under topical anesthesia (Figure 2).

The VDM measurement was used as the reference meridian. The degree of meridian marking error was measured by calculating the difference and direction of the SDVM and HSBM marking points from the VDM reference point (Figure 2). As differences were observed in both the clockwise and the counter-clockwise directions, we defined both negative (relative excyclotorsion) and positive (relative incyclotorsion) values for the purpose of quantification and calculation (Figure 3). Relative cyclotorsion is the summation of the relative in- and excyclotorsion values.

\section{Statistical data analysis}

Paired $t$-test was used to compare the mean differences and standard deviations of the SDVM or HSBM versus the VDM

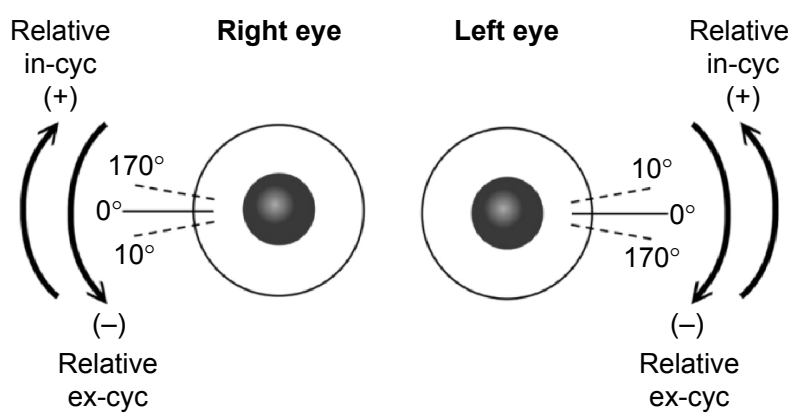

Figure 3 Examples of relative incyclotorsion (in-cyc) and excyclotorsion (ex-cyc). reference marks. SPSS 19.0.0 software (SPSS, Inc., Chicago, IL, USA) was used for the statistical analysis.

\section{Results}

In this study, the SDVM group included 81 eyes (61 patients), and the HSBM group included 56 eyes (36 patients). The overall mean patient age was $65.70 \pm 13.14$ (range: $32-91$ ) years. Of the patients, $30 \%$ (25 eyes) had corneal marking points that were difficult to identify (eg, washout of marks).

In relation to the VERION horizontal reference meridian, the $\operatorname{SDVM}\left(-3.46^{\circ} \pm 7.32^{\circ}\right.$, range: $-18^{\circ}$ to $\left.13^{\circ}\right)$ exhibited greater average relative cyclotorsion, compared with the $\operatorname{HSBM}\left(0.41^{\circ} \pm 4.92^{\circ}\right.$, range: $-10^{\circ}$ to $\left.10^{\circ}\right)$. We also calculated average misalignment as the mean absolute value of the total angle differences and found that the mean average misalignment was significantly less in the HSBM group than in the SDVM group ( $t=4.179, P<0.001$; Table 1$)$. Similarly, the HSBM yielded a lower mean relative cyclotorsion in the left and right eyes when compared with the SDVM (Table 1).

In a lateral comparison, the left eyes exhibited a greater difference in relative excyclotorsion, compared with the right eyes. In the right eye, the mean SDVM and HSBM angles were $1.33^{\circ} \pm 6.91^{\circ}$ (range: $-13^{\circ}$ to $13^{\circ}$ ) and $0.48^{\circ} \pm 4.96^{\circ}$ (range: $-10^{\circ}$ to $10^{\circ}$ ), respectively; in the left eye, the corresponding angles were $-7.29^{\circ} \pm 5.07^{\circ}$ (range: $-18^{\circ}$ to $5^{\circ}$ ) and $-0.03^{\circ} \pm 4.99^{\circ}$ (range: $-10^{\circ}$ to $10^{\circ}$; Table 2 ).

\section{Discussion}

Our study results demonstrate that while using the VDM as the reference meridian, average misalignments of $6.94^{\circ}$ and $3.66^{\circ}$ were observed with the SDVM and HSBM, respectively. Using the previously mentioned ratio of a $3 \%-3.5 \%$ increase in residual astigmatism for every $1^{\circ}$ of axis misalignment during toric IOL implantation, ${ }^{5}$ a $30^{\circ}$ misalignment would yield a $100 \%$ rate of residual astigmatism., Although the average misalignments yielded by the methods

Table I Relative cyclotorsion and average misalignment with subjective direct visual marking and horizontal slit beam marking, using the VERION digital marker as a reference

\begin{tabular}{llll}
\hline & $\begin{array}{l}\mathbf{N} \\
\text { (eyes) }\end{array}$ & $\begin{array}{l}\text { Relative } \\
\text { cyclotorsion } \\
\text { Mean } \pm \mathbf{S D} \text { (range) }\end{array}$ & $\begin{array}{l}\text { Average } \\
\text { misalignment } \\
\text { Mean } \pm \mathbf{S D} \text { (range) }\end{array}$ \\
\hline Subjective direct & 81 & $-3.46^{\circ} \pm 7.32^{\circ}$ & $6.94^{\circ} \pm 4.12^{\circ}$ \\
visual marking & & $\left(-18^{\circ}\right.$ to $\left.13^{\circ}\right)$ & $\left(0^{\circ}\right.$ to $\left.18^{\circ}\right)$ \\
Horizontal slit & 56 & $0.41^{\circ} \pm 4.92^{\circ}$ & $3.66^{\circ} \pm 3.28^{\circ}$ \\
beam marking & & $\left(-10^{\circ}\right.$ to $\left.10^{\circ}\right)$ & $\left(0^{\circ}\right.$ to $\left.10^{\circ}\right)$ \\
\hline
\end{tabular}

Abbreviation: SD, standard deviation. 
Table 2 Comparison of right eye and left eye cyclotorsion

\begin{tabular}{|c|c|c|c|c|}
\hline & \multicolumn{2}{|l|}{ Right eye } & \multicolumn{2}{|l|}{ Left eye } \\
\hline & $\begin{array}{l}\text { Subjective direct } \\
\text { visual marking }\end{array}$ & $\begin{array}{l}\text { Horizontal slit } \\
\text { beam marking }\end{array}$ & $\begin{array}{l}\text { Subjective direct } \\
\text { visual marking }\end{array}$ & $\begin{array}{l}\text { Horizontal slit } \\
\text { beam marking }\end{array}$ \\
\hline Eyes & $n=36$ & $n=25$ & $\mathrm{n}=45$ & $n=31$ \\
\hline $\begin{array}{l}\text { Mean relatively cyc Angle, } \\
\text { degrees }(\text { mean } \pm S D)\end{array}$ & $1.33^{\circ} \pm 6.91^{\circ}$ & $0.48^{\circ} \pm 4.96^{\circ}$ & $-7.29^{\circ} \pm 5.07^{\circ}$ & $-0.03^{\circ} \pm 4.99^{\circ}$ \\
\hline Mean relatively ex-cyc, (n) \% & (14) $38.89 \%$ & (9) $36.00 \%$ & (39) $86.67 \%$ & (I3) $41.94 \%$ \\
\hline Angle, degrees (mean $\pm S D$ ) & $6.14^{\circ} \pm 3.28^{\circ}$ & $4.22^{\circ} \pm 2.99^{\circ}$ & $8.59^{\circ} \pm 4.02^{\circ}$ & $4.54^{\circ} \pm 2.90^{\circ}$ \\
\hline Mean relatively in-cyc, (n) \% & (22) $61.11 \%$ & (16) $64.00 \%$ & (6) $13.33 \%$ & (I8) $58.06 \%$ \\
\hline Angle, degrees (mean $\pm S D$ ) & $6.09^{\circ} \pm 3.45^{\circ}$ & $3.13^{\circ} \pm 3.72^{\circ}$ & $1.17^{\circ} \pm 2.04^{\circ}$ & $3.22^{\circ} \pm 3.35^{\circ}$ \\
\hline
\end{tabular}

Notes: Relative excyclotorsion: right eye exhibits a counter-clockwise angle difference from the VERION digital marker, or left eye exhibits a clockwise angle difference. Relative incyclotorsion: right eye exhibits a clockwise angle difference from the VERION digital marker, or left eye exhibits a counter-clockwise angle difference.

Abbreviations: SD, standard deviation; cyc, cyclotorsion; ex-cyc, excyclotorsion; in-cyc, incyclotorsion.

evaluated in this study were not so drastic, the observed small increments in misalignment lead to noticeable increases in residual astigmatism.

Nguyen and Miller were the first to describe a computerassisted technique for determining the axis of alignment of a toric IOL. ${ }^{9}$ Previously, surgeons relied only on keratometric readings and dilated slit lamp examinations to approximate the axis of implantation and perform corneal marking, respectively. Since the introduction of computer assistance, multiple digital methods for determining the axis of toric IOL implantation have been developed, including the VERION Image Guided System, Zeiss Cataract Suite Markerless (Carl Zeiss Meditec AG, Jena, Germany), and TrueGuide (TrueVision 3D Surgical, Santa Barbara, CA, USA).

Our findings suggest that of the two tested nondigital methods, the HSBM technique yielded the least rotational deviation relative to the digital reference meridian. Igarashi et $\mathrm{al}^{4}$ previously reported an axis misalignment with an HSBM of $3.4^{\circ} \pm 2.2^{\circ}$ (range: $0^{\circ}-8^{\circ}$ ), similar to the $3.66^{\circ} \pm 3.28^{\circ}$ (range: $0^{\circ}-10^{\circ}$ ) recorded in our study. Igarashi et al ${ }^{4}$ quantitatively assessed the degree of axis misalignment by measuring the difference from the horizontal corneal topography reference line to the line that connected the two marking points in the image, whereas our study used the VDM horizontal meridian as a reference.

Currently, the HSBM is the most popular corneal marking method. ${ }^{10-12}$ The cornea is not a perfect circle and often exhibits a variable diameter; accordingly, it is easy to inadvertently displace the horizontal slit beam marker above or below the meridian. It is also challenging to identify the true 3- and 9-o'clock positions. Farooqui et a ${ }^{13}$ recently described two novel methods for marking the limbus, namely, the "bubble" and the "pendulum", in an effort to make horizontal marks in proximity to the 3- and 9-o'clock positions. These authors observed an average misalignment of $3^{\circ}$ with each of their novel methods; however, we must note the several problems associated with these methods and all methods that use ink to mark the limbus. First, the use of an ink marker may constitute a possible infection source. Second, and most important, pen marks on the eye may migrate, blur, fade, or even disappear during surgery, especially if corneal irrigation is used. In this study, we were unable to identify the precise locations of ink markers on 25 eyes (30\%) owing to washout. Accordingly, efforts have been made to introduce corneal marking methods that do not involve the use of ink, such as the Wet-Field Osher ThermoDot (Beaver-Visitec International, Waltham, MA, USA), which was developed by Osher. ${ }^{14}$ Osher ${ }^{14}$ has also demonstrated that the use of iris landmarks and intraoperative keratoscopy could improve the accuracy of toric IOL alignment.

Notably, several factors contribute to make the SDVM technique the least reliable method. Cyclotorsion will inevitably occur when a patient moves from an upright to a supine position while under a surgical microscope. Studies of upright-to-supine cyclotorsion have generally reported values ranging from $2^{\circ}$ to $4^{\circ}$, although individual values may be greater. ${ }^{15-17}$ Furthermore, our study reveals that the same right-handed surgeon marked both the right and the left eyes while using his dominant hand, a factor that might explain why the degree of axis misalignment differed between the left and right eyes. Likewise, the placement of the incision hand relative to the marking might have resulted in some variability between the right and left sides. Because we found significant differences between the right eye and the left eye in manual marking with the right-handed surgeon, we included cases of two eyes of the same patient. Additional limitations of our study include the retrospective nature and relatively small number of patients. In future, randomized controlled prospective studies of the HSBM versus VERION 
digital marking that use cylinder power reduction after toric IOL implantation as the outcome measure will be needed to validate the accuracy of the VERION system relative to the HSBM.

\section{Conclusion}

Unlike the HSBM, VDM appears to be a reliable marking method that remains unaffected by potential ink marker washout, a major potential drawback of the HSBM. In contrast, the SDVM is not an entirely reliable method. The use of VDM on the surgical table might prevent inaccurate preoperative manual marking prior to toric IOL implantation.

\section{Disclosure}

The authors report no conflicts of interest in this work.

\section{References}

1. Carey PJ, Leccisotti A, McGilligan VE, Goodall EA, Moore CB. Assessment of toric intraocular lens alignment by a refractive power/corneal analyzer system and slit lamp observation. J Cataract Refract Surg. 2010; 36:222-229.

2. Popp N, Hirnschall N, Maedel S, Findl O. Evaluation of 4 corneal astigmatic marking methods. J Cataract Refract Surg. 2012;38:2094-2099.

3. Woo YJ, Lee H, Kim HS, Kim EK, Seo KY, Kim TI. Comparison of 3 marking techniques in preoperative assessment of toric intraocular lenses using a wavefront aberrometer. J Cataract Refract Surg. 2015;41: 1232-1240.

4. Igarashi A, Kamiya K, Shimizu K. Clinical evaluation of accuracy of horizontal meridian limbal marking. Optom Vis Sci. 2013;90:540-545.

5. Hill W, Potvin R. Monte Carlo simulation of expected outcomes with the AcrySof $^{\circledR}$ toric intraocular lens. BMC Ophthalmol. 2008;8:22.
6. Thomas BC, Mueller A, Auffarth GU, Holzer MP. Influence on intraocular lens power calculation of corneal radii measurement using an image-guided system. J Cataract Refract Surg. 2016;42(11): 1588-1594.

7. Ma JJ, Tseng SS. Simple method for accurate alignment in toric phakic and aphakic intraocular lens implantation. J Cataract Refract Surg. 2008;34:1631-1636.

8. Shimizu K, Misawa A, Suzuki Y. Toric intraocular lenses: correcting astigmatism while controlling axis shift. J Cataract Refract Surg. 1994; 20:523-526.

9. Nguyen TM, Miller KM. Digital overlay technique for documenting toric intraocular lens axis orientation. J Cataract Refract Surg. 2000; 26:1496-1504.

10. Bayramlar H, Dag Y, Karadag R, Cakici O. An easy and practical method for toric intraocular lens implantation: marking corneal astigmatic axis at slit-lamp. Int Ophthalmol. Epub 2016 May 12.

11. Bayramlar H, Dag Y, Sadigov F. Comments on corneal astigmatic marking methods. J Cataract Refract Surg. 2013;39:966.

12. Roumeliotis G, Hutnik C. A simple, reproducible, and cost effective axis marking system for toric lens implantation. J Refract Surg. 2012;28: $12-13$.

13. Farooqui JH, Koul A, Dutta R, Shroff NM. Comparison of two different methods of preoperative marking for toric intraocular lens implantation: bubble marker versus pendulum marker. Int J Ophthalmol. 2016; 9:703-706.

14. Osher RH. Iris fingerprinting: new method for improving accuracy in toric lens orientation. J Cataract Refract Surg. 2010;36:351-352.

15. Arba-Mosquera S, Merayo-Lloves J, de Ortueta D. Clinical effects of pure cyclotorsional errors during refractive surgery. Invest Ophthalmol Vis Sci. 2008;49:4828-4836.

16. Chernyak DA. Cyclotorsional eye motion occurring between wavefront measurement and refractive surgery. J Cataract Refract Surg. 2004;30:633-638.

17. Swami AU, Steinert RF, Osborne WE, White AA. Rotational malposition during laser in situ keratomileusis. Am J Ophthalmol. 2002; 133:561-562.
Clinical Ophthalmology

\section{Publish your work in this journal}

Clinical Ophthalmology is an international, peer-reviewed journal covering all subspecialties within ophthalmology. Key topics include: Optometry; Visual science; Pharmacology and drug therapy in eye diseases; Basic Sciences; Primary and Secondary eye care; Patient Safety and Quality of Care Improvements. This journal is indexed on

Submit your manuscript here: http://www.dovepress.com/clinical-ophthalmology-journal

\section{Dovepress}

PubMed Central and CAS, and is the official journal of The Society of Clinical Ophthalmology (SCO). The manuscript management system is completely online and includes a very quick and fair peer-review system, which is all easy to use. Visit http://www.dovepress.com/ testimonials.php to read real quotes from published authors. 